\title{
Collecting Critical Data to Assess the Sustainability of Rural Infrastructure in Low-Income Countries
}

\section{Sharon A. Jones ${ }^{1, *}$, Kristen L. Sanford Bernhardt ${ }^{2, \dagger}$, Mark Kennedy ${ }^{1, \dagger}$, Kelsey Lantz ${ }^{3}$ and Trent Holden ${ }^{1}$}

1 Civil Engineering Program, University of Portland, 5000 N. Willamette Blvd., Portland, OR 97203, USA; E-Mails: kennedy@up.edu (M.K.); holden14@up.edu (T.H.)

2 Department of Civil and Environmental Engineering, Lafayette College, Easton, PA 18042, USA;

E-Mail:sanfordk@lafayette.edu

3 Department of Civil Engineering, Clemson University, Clemson, SC 29634, USA;

E-Mail: lantzk1@gmail.com

$\dagger$ These authors contributed equally to this work.

* Author to whom correspondence should be addressed; E-Mail: joness@up.edu; Tel.: +1-503-943-8168; Fax: +1-503-943-7997.

Received: 24 September 2013; in revised form: 25 October 2013 / Accepted: 4 November 2013 / Published: 12 November 2013

\begin{abstract}
Rural water systems in low-income countries often fail to deliver potable water sustainably. Reasons include socio-economic, financial, and technical challenges that are specific to the community. Improved assessment methods are critical if decision makers want to provide sustainable solutions; however, to be useful, such methods require substantial data about the complex interaction between people, water, and infrastructure. Such interaction is affected by, and in turn, affects the behavior of community members regarding water usage, resources for infrastructure maintenance, and choice of assets. Unfortunately, much of these data are not readily available, in a large part because of the site-specific context associated with each rural community. Because of the difficulty and expense in obtaining site-specific data, it is important to identify the most critical needs for field studies versus the data that can be obtained from sources such as non-governmental organizations and the general literature. We examine this issue by first using an extensive data set from Malawi to identify the critical data needs. We then present several examples of field studies in Honduras and Uganda where we collected some of that critical data. Throughout, we discuss best practices for conducting and using focused field studies versus the general literature.
\end{abstract}


Keywords: water; rural; sustainable; data; assessment

\section{Introduction}

Despite progress in providing sustainable access to safe drinking water (part of U.N. Millennium Development Goal 7 and a contributing element to most of the other Millennium Development Goals), many water systems in the developing world fail within a few years of installation. For example, a 2009 WaterAid study from Tanzania found that nearly half of improved public water points in rural areas are not functioning, and $25 \%$ of systems are inoperable after only two years following installation [1]. These systems fail at such high rates in large part because the sustainability of a rural water system in a low-income country depends on "the relationship of the user with the life cycle of the water system" [2]. For example, Masduqi et al. conclude that water system sustainability in Indonesia is influenced significantly by technology selection, water sources, investment cost, operator capability, availability of spare parts, operation cost, technical operation, community participation, and institutional management [3]. Similarly, Schweitzer et al. examined the predictors of sustainable water system management in the Dominican Republic and found the highest correlation with life cycle characteristics such as system age, plumber wages, and time spent on maintenance [4].

Given the complex interaction between users and the systems, assessing the sustainability of a water system choice in a particular community requires data about user preferences and decision-making behavior in regards to water, as well as the construction, operation, maintenance, and demolition characteristics of the system within its environmental space. Jones et al. describe in detail more than 50 factors and units of measure that can affect whether a system is sustainable over its design life [2]. These sustainability factors are extensive and fit into technical, environmental, institutional, community and managerial, financial, and human health categories [2]. Unfortunately, those responsible for assessment modeling typically have to rely on only a subset of the most critical data to keep the process simple while maintaining enough detail to produce useful results.

As an example of how simplifying the data needs is important, two of the co-authors have been involved in an ongoing effort that uses agent-based modeling to simulate the sustainability of various rural water system alternatives in hypothetical communities over the design life of the infrastructure. The goal is to demonstrate that agent-based modeling can be an effective tool for predicting the outputs of these complex interactions involving infrastructure, human behavior, and the natural environment. However, the data requirements for this effort have proved to be daunting for the reasons described previously. As a result, we have had to make choices about what inputs to use, what outputs to measure, and what proxies to use for variables that may be too complex to model, but can still provide insights that can help decision makers.

The goal for this project was to identify the critical data for effective sustainability assessment, evaluate what can best be obtained from the literature versus what can best be obtained from field studies, and discuss best practices for such data collection along with challenges and solutions. We first present a brief overview of the field study locations. This is followed by an analysis of data from one of those sites that illustrates the locally specific data needed for typical sustainability assessments. 
We use these case-specific results combined with the literature to organize the critical data needs according to user characteristics, water system characteristics, and water board characteristics. For each category, we discuss the types of generic data that might be published and why they may not be appropriate for sustainability assessments. We then present examples of how field studies can be used to provide the necessary input data and conclude with best practices for such data collection and application.

\section{Overview of Field Study Sites}

Our field data are drawn from three locations: Malawi, Honduras, and Uganda. Table 1 summarizes the key characteristics for each field study site and the sections below provide additional background.

Table 1. Key Characteristics of field study sites.

\begin{tabular}{llll}
\hline & Malawi & Honduras & Uganda \\
\hline Study date & December 2009 to January 2010 & Summers 2010 and 2012 & Summer 2012 \\
\hline Study location & $\begin{array}{l}\text { Area surrounding Blantyre } \\
\text { (peri-urban to rural) }\end{array}$ & $\begin{array}{l}\text { San Antonio Cortes } \\
\text { district (rural) }\end{array}$ & $\begin{array}{l}\text { Queen Elizabeth } \\
\text { National Park (rural) }\end{array}$ \\
\hline Partner organization & World Water Corps & Water for People & Fontes Foundation \\
\hline $\begin{array}{l}\text { Country GDP per capita } \\
\text { in 2011 (United Nations) }\end{array}$ & $\$ 388$ & $\$ 2,250$ & $\$ 558$ \\
\hline $\begin{array}{l}\text { No. of villages } \\
\text { or communities }\end{array}$ & $\begin{array}{l}\text { 21 low-income areas, each with } \\
\text { several communities }\end{array}$ & 3 villages & 3 villages \\
\hline $\begin{array}{l}\text { Improved water system } \\
\text { type if applicable }\end{array}$ & $\begin{array}{l}\text { Community tap stands } \\
\text { and kiosks }\end{array}$ & N/A & Community tap stands \\
\hline Data collected & Water supply conditions & $\begin{array}{l}\text { Water usage and water } \\
\text { collection travel time }\end{array}$ & $\begin{array}{l}\text { Finances for improved } \\
\text { water systems }\end{array}$ \\
\hline Data collection methods & $\begin{array}{l}\text { Surveys of households, } \\
\text { community water points, and } \\
\text { public institutions }\end{array}$ & $\begin{array}{l}\text { Household surveys, and } \\
\text { time and motion studies }\end{array}$ & $\begin{array}{l}\text { Review of financial } \\
\text { records, and } \\
\text { household surveys }\end{array}$ \\
\hline
\end{tabular}

\subsection{Malawi Villages}

Data was collected in Blantyre, Malawi over two trips between December 2009 and January 2010 by 26 volunteers as part of a World Water Corps ${ }^{\odot}$ (WWC) (World Water Corps ${ }^{\circledR}$ is the volunteer branch of Water for People) effort to complete baseline assessment surveys in the city's 21 low-income areas (LIAs). One of the coauthors of this paper served as a volunteer. LIAs are unplanned settlements near the city with most residents categorized as poor. Blantyre is the second largest city in Malawi, with approximately 660,000 people according to the most recent Census [5]. The LIAs are located in the peri-urban area of Blantyre and increase the population of the Blantyre region to approximately 1 million. While referred to as peri-urban, many of these LIAs display characteristics more in common with rural areas in terms of population density, distance to urban center, reliance on subsistence agriculture, and so on.

One to two WWC volunteers teamed up with one to two Water For People (WFP) (Water for People is an international, non-profit humanitarian organization that collaborates with local businesses, volunteer organizations, governments, and communities to create innovation and collaborative 
solutions that allow partner communities to construct, operate, and maintain their own sustainable drinking water systems, sanitation facilities, and hygiene education programs. The vision of the organization is to create a global community where all people have access to improved drinking water and sanitation services, and where no one is affected by or dies from water- or sanitation-related) Malawi staff members and local partners to map and survey an assigned LIA. The teams collected mapping and baseline data at each communal water point to capture the water supply and sanitation conditions at the community level. The teams also conducted household surveys to capture water supply and sanitation conditions at the household level. Each team used a standardized set of mapping and survey instruments developed by WFP (The survey questions can be found at Reference [6]). Teams surveyed every fifth house along streets, or footpaths in their assigned LIA. If the occupant of the selected house was not home, the team made a note of its location and continued to the next house according to the sampling method. At the end of the field day, the team returned to each skipped house to check again whether the resident was home. If he/she was not home, the team would survey the house next door in the direction they had been surveying that day.

According to WFP, for a system to be considered fully functional, water must be available in adequate quantity and quality, the system must meet all government standards, and there must be an absence of broken parts and operational problems [6]. A system is considered to have an "okay" or adequate functional status if water is flowing, but the system fails to provide an acceptable quantity or quality. In addition, these systems fail to meet established government standards, and/or exhibit broken parts, leaks, or other operational difficulties [6]. Finally, WFP defines a system as non-functional if absolutely no water flows from the system [6].

WFP provided one of the coauthors of this paper with the survey data for research purposes after normalizing the data to account for interpretation differences and biases among interviewers and interviewees. The data set is substantial and is subdivided into three categories according to the stakeholder surveyed: household, public institution, and community water point (community water seller). Combined, these three categories represent 7,231 individual observations. Of these 7,231 observations, the household, public institution, and community water point data account for 664,147, and 543 observations, respectively. Despite the extensive nature of the data set, there are several thousand instances of incomplete questions on the surveys that result in some missing data.

\subsection{Honduras Villages}

Two of the co-authors conducted field studies for travel time and water usage in three rural Honduran communities in 2010 and 2012. All three communities are located in the San Antonio, Cortes district of northwest Honduras. The terrain in San Antonio is generally hilly and the livelihood for most of the rural families is subsistence farming. Water sources for the families that we studied were mostly small, shallow, hand-dug wells "positos", or piped spring water. In other words, these villages did not have improved water systems. Our partner organization, WFP, helped us select water carriers for the travel time studies based on the carriers' willingness to participate and their location relative to the water sources. For example, we tried to identify as many different routes to water sources as possible and to minimize the number of water gathering trips that used the same route. 
In each community, the number of water carriers participating in the study represented about $20 \%$ of the total families.

We timed water carriers (mostly women and children) traveling to and from water sources and determined the distance traveled and the corresponding elevation change using hand-held GPS units. We also interviewed each of the families participating in the travel time studies (using Honduran interpreters) to determine practices related to water usage, and queried water carriers on the number and time of day that water-gathering trips were conducted, along with number and volume of water containers carried on each trip. Using these interviews, we also determined the major uses for water and the type of treatment used if applicable.

\subsection{Uganda Villages}

One of the co-authors conducted field studies to gather data on the impacts and finances of improved water systems in three rural villages in Western Uganda in 2012 [7]. All three communities are located within the boundaries of Queen Elizabeth National Park, a national wildlife preserve. A private charity, the Fontes Foundation (The Fontes Foundation is a small Norwegian NGO whose vision is to generate appropriate solutions in order to meet the needs of communities in developing countries. The organization prioritizes community work and uses a personalized, participatory approach in each intervention in Uganda and Mozambique. Through the development of basic infrastructure such as water supply, sanitation and education facilities, the Fontes Foundation aims to improve the standard of living and well being in developing countries. In addition to the mobilization and transfer of funds, the Fontes Foundation believes that its main contribution lies in reducing the knowledge gap between developed and developing countries. Therefore, emphasis will be on capacity building in the local communities, based on exchange and cooperation. Through encouragement, trust, recognition and follow up, individuals and communities are motivated to take a first step and improve their living situation, a small step towards development.), has provided each community with a water distribution and filtration system that processes surface water and ranges in age from one to eight years. Water is purchased by the $20 \mathrm{~L}$ jerry-can at a community tap stand, and a member of the water user committee is responsible for collecting payment. The three communities have populations of 530, 770, and 710 people with three, two, and two tap stands, respectively. Communities without improved water systems rely on rainwater and untreated surface water sources; the former is unreliable in terms of quantity, and the latter has high levels of contaminants.

We gathered quantitative and qualitative data about water service delivery and the corresponding impact on the community, including the community's governance of the system. We also interviewed water users and transcribed information from water committee record books. In addition, we digitized handwritten reports from the community water committees to the charity office in Kampala that recorded financial and operational data for the systems.

\section{Critical Data Needs}

Of the 410 communities in the 21 LIAs with improved systems that were surveyed in Malawi, $35 \%$ of the water points had fully functioning status, $39 \%$ had adequately functioning status, and $26 \%$ were 
considered failed systems. To identify the critical needs, we used two different statistical approaches to analyze this data as described below.

\subsection{Methodology}

With the first approach, we relied on the results from a study completed by Weir [6]. In that study, Weir used the Malawi survey data to identify the predictive characteristics of communities with fully functioning (sustainable) water systems by performing an ordered-probit regression analysis for the household user, the institutional user (e.g., schools and clinics), and the community water seller (as a representative of the community water board). The dependent variables are the technical sustainability outcomes of the water infrastructure in terms of accessibility, quantity, and quality operationalized as poor sustainability (failed system status), questionable sustainability (adequately functioning status), and high sustainability (fully functioning status) [6]. Unfortunately, the sustainability outcomes collected in the surveys are limited to these technical characteristics and do not include factors for human health and environmental impact given the nature of the dataset. The independent variables are various characteristics about the three stakeholders chosen from the institutional, community/managerial, and financial sustainability characteristics identified by Weir and Jones [2,6].

In the second approach, we relied on the user perceptions from the household survey data to identify the descriptive characteristics that are critical for sustainability assessments. We performed a statistical comparison of those household users who were satisfied versus those who were dissatisfied with their improved community water system. We used a two-tail $\mathrm{Z}$ test for two population proportions with a five percent confidence interval and a null hypothesis as follows: There is no difference in the proportion of responses to the questions below for the populations of "Satisfied" versus "Dissatisfied" households. We determined the populations of households that were "Satisfied" versus "Dissatisfied" with their community water system using the response to question 26 in the household survey that specifically addressed this issue. For example, for the question "If the house does not have a tap stand, is it willing to get one?" we compared the percent of households in the Satisfied population that answered "no" versus the percent of households in the Dissatisfied population that answered "no". Similarly, for a question such as "What is the primary way you treat your water at home?" we compared the percent of households in the Satisfied population that answered "no treatment" versus the percent of households in the Dissatisfied population that had the same answer, and so on for the various possible answers. In other words, we determined how households varied in their responses depending on whether they were satisfied or not with their improved water system in the hope that these differences represent critical data that need to be collected. We assume that those characteristics that differ significantly between the two populations represent the types of local-context data that are needed for sustainability assessments.

\subsection{Results}

The results from the regression analysis revealed that the household user, the institutional user, and the community water seller each display several characteristics important for predicting water system sustainability [6]. These include: (a) the household user's willingness to actively participate in all phases of system implementation and life-cycle management, (b) how the household user applies the 
collected water or the range of uses for the collected water, (c) the living standards for the community, (d) infrastructure investment, by the community (e) the living patterns for the community, and (f) the ownership structure for the water system [6]. The author notes that the results include some contradictions both within the regression analysis itself, and as compared to other studies due to limitations caused by the lack of an uniform operational definition of sustainability [6]. These limitations are in addition to those already noted due to the lack of data regarding environmental and health outcomes.

The results from the proportions test show that there are several questions in the Malawi survey of household users that yield significantly different responses based on whether that population is satisfied or not with its improved water system, as follows:

- If the house does not have a tap stand, is it willing to get one?

- Does the improved system provide drinking water every day of the year?

- Are there water shortages from the primary source during the dry season?

- Are there water shortages from the primary source during any other season?

- Does your household get enough water every day from your primary improved source for drinking?

- If you do not have enough water for drinking, what is the primary reason? (long lines vs. political reasons $v s$. failure to pay)

- Is water from the improved source used for other productive purposes?

- Do you have enough water from the improved source for those productive purposes other than drinking every day?

- Do you travel more than 500 meters to collect drinking water?

- What is the primary way you treat your water at home (no treatment $v s$. boiling $v s$. chlorine $v s$. safe storage)

- Do you pay a tariff or user fee for water from an improved source

- If household has a tap, does the tap/tap stand leak?

The results from the proportions test also show that there are questions that did not result in significantly different responses based on whether a population is satisfied or not with its improved water system, as follows:

- Is there an individual tap stand at the house?

- Is the house able to pay for an individual water connection?

From the proportions test, we conclude that to perform successful sustainability assessments, data are needed regarding various household user characteristics such as willingness to pay for capital improvements and ongoing operation and maintenance (O\&M), but not necessarily ability to pay, etc. In addition, data about the design of the water system and the overall community capacity are needed at the aggregate level. In particular, design characteristics such as the distance to the improved water system (tap stand, etc.) appears to be more important than whether the tap stand is at the actual home when determining sustainability.

\subsection{Inventory of Critical Data Needs}

Using the results of the two statistical approaches applied to the Malawi field study data, we identified the critical data input needs for assessing the sustainability of a rural water system as shown 
in Table 2. We also used the results to identify whether field studies are necessary to obtain the data. Note that this summary assumes that resources exist for the capital project(s) required to initially install an improved water system using external aid, community collective resources, or some combination. In other words, our focus is on the sustainable O\&M of the system over its design life. In Table 3, we then summarize the types of sustainability outputs we can expect from this approach to assessment, again identifying which must be obtained through fieldwork.

Table 2. Sustainability modeling inputs for low-income rural water systems.

\begin{tabular}{|c|c|}
\hline Critical Data Inputs & Fieldwork Required? \\
\hline User Characteristics & \\
\hline $\begin{array}{l}\text { water system preference } \\
\text { user applications of the water } \\
\text { diurnal water usage } \\
\text { population growth } \\
\text { user travel (outbound speed, inbound speed, wait/queue time) } \\
\text { overall willingness to participate in system implementation and } \\
\text { management (proxy: willingness to pay for O\&M) } \\
\text { Water System Characteristics }\end{array}$ & $\begin{array}{l}\text { Yes for all inputs other than } \\
\text { population growth. }\end{array}$ \\
\hline $\begin{array}{l}\text { water source type } \\
\text { water source quantity (seasonal, flow) } \\
\text { water source quality (pathogens, other contaminants) } \\
\text { improved } v s \text {. unimproved } \\
\text { collection type } \\
\text { treatment type (potable } v s . \text { non potable) } \\
\text { distribution type } \\
\text { distance to improved water system (if applicable) } \\
\text { water system capacity (proxy: potential number of households can serve) } \\
\text { water system condition } \\
\text { number of households served } \\
\text { capital costs } \\
\text { O\&M costs }\end{array}$ & $\begin{array}{l}\text { Yes for all inputs other than } \\
\text { cost data. }\end{array}$ \\
\hline Water Board (or Water User Committee) Characteristics & \\
\hline $\begin{array}{l}\text { infrastructure repair capacity } \\
\text { tariff level decision metrics } \\
\text { removal of household from service decision metrics } \\
\text { availability of repair/O\&M expertise } \\
\text { availability of spare parts }\end{array}$ & Yes for all inputs. \\
\hline
\end{tabular}

The WHO and UNICEF Joint Monitoring Programme is the official arm of the United Nations that is tasked with monitoring progress towards the Millennium Development Goals for access to water and sanitation. As such, this group has substantial published data (that are updated regularly) for each country at the aggregate level. These data are important in terms of macro-scale global and regional comparisons, as well as comparisons between urban and rural sectors; however, the data do not include details for individual communities. In addition, the data are limited to infrastructure and do not include 
the human components that affect sustainability that we refer to as "user characteristics". Many of the other government and NGO-sponsored databases and clearing-houses are similar.

Table 3. Sustainability modeling outputs for low-income rural water systems.

\begin{tabular}{|c|c|}
\hline Critical Data Outputs & Fieldwork Required? \\
\hline Water System Characteristics & \\
\hline $\begin{array}{l}\text { demand } v s \text {. supply (daily } v s . \text { seasonal) } \\
\text { system failure (service disruption) } \\
\text { environmental impact (energy required, raw materials required, hazardous } \\
\text { materials required, habitat loss, pollutant loading, water loss/transfer) } \\
\text { User Characteristics }\end{array}$ & $\begin{array}{l}\text { Yes for all outputs other } \\
\text { than some of the } \\
\text { environmental impacts. }\end{array}$ \\
\hline $\begin{array}{l}\text { marginal health (proxy: potable } v s . \text { non-potable water system) } \\
\text { marginal wealth (proxy: water collection time) } \\
\text { user satisfaction }\end{array}$ & Yes for all outputs. \\
\hline
\end{tabular}

There are of course several published articles that address many of the characteristics noted in Tables 2 and 3. The most useful of these rely on case studies to present a set of variables that influence user (or water board) choice, or summarize a range of alternatives to consider. These studies can be used to focus the scope of subsequent fieldwork, however they do not replace such fieldwork. As an example, Nyong and Kanaroglu present the results of a case study that examines how a household user selects a water source (i.e., a user's water system preferences) [8]. Based on this fieldwork, the authors show that "time and place" decision factors influence a household user's selection of a particular water source, and they provide the prioritization specific to the village they studied in semi-arid northern Nigeria [8]. Their conclusion and the list of decision factors provide a starting point for someone who wants to evaluate sustainability in another location (and perhaps at another time), but it does not replace the need for field studies. In other words, fieldwork and site specific data are needed for those user characteristics, water system characteristics, and water board characteristics that involve human choice (how much water do I use, where should I collect water, should I pay the tariff, should we repair the system, etc.).

Even so, the published literature can be used to determine several of the life-cycle economic and environmental impacts of the water system infrastructure once the user choices and the water board choices are known. As an example, Jones et al. [2] demonstrate how published data from suppliers and case studies can be used to extrapolate the life-cycle impacts for a variety of potable water scenarios for a hypothetical community of 65 homes and 256 inhabitants, in a one $\mathrm{km}^{2}$ community area. Using this hypothetical community, the authors are able to demonstrate that there are few differences in costs and environmental impacts for many improved rural water system alternatives with one exception [2]. If the hydrogeology allows, they show that an improved water system that uses groundwater with community standpipes is substantially lower in cost with a low environmental inventory [2]. They also show that the O\&M phase has the biggest sustainability impact over the life cycle of these rural water systems [2]. As such, the O\&M phase can be used as a proxy for total life-cycle financial and environmental costs for rural water systems.

Jones et al. also show that manual collection systems (unimproved) with point-of-use treatment to provide potable water have the lowest life-cycle costs (economic and environmental) when the 
intangible cost (and social cost) of water collection time is not accounted for [2]. Of course, such social costs are a critical factor in the overall sustainability of rural water systems in low-income communities and in fact can be used as proxies for several of the outputs of a sustainability assessment shown in Table 2. Outputs such as water collection time depend on user choice and asset location that can only be determined with focused field studies.

In summary, the published literature can be a valuable source for aggregate information that helps the assessment team to understand the context for that country, region, and community. It can also provide a starting point for the types of field data that will need to be collected so that focused interview protocols and other data collection instruments can be developed. And, once the behavior of the stakeholders is known from fieldwork, the published literature can provide necessary information about economic and environmental impacts. However, there is no substitute for field studies to collect the critical, locally specific input and output data necessary for accurate sustainability assessments of rural water systems in low-income communities. The rest of this paper discusses some examples of how such studies can be conducted along with best practices and common challenges.

\section{Field Studies for User Characteristics}

As stated previously, the locally specific data about user characteristics (inputs and outputs) that are typically needed for sustainability assessments include:

- water system preference

- user applications of the water

- diurnal water usage

- user travel (outbound speed, inbound speed, wait/queue time)

- overall willingness to participate in system implementation and management (proxy: willingness to pay for O\&M)

- marginal health (proxy: potable $v s$. non-potable water system)-same as water system preference

- marginal wealth (proxy: water collection time)-based on user travel data

- user satisfaction

Below are several examples of collecting focused field data in this category.

\subsection{Diurnal Water Usage}

Although generic water usage data is available in the published literature, geographical specificity of the diurnal water demand is lacking. A minimum of $7.5 \mathrm{~L}$ per capita per day has been reported for meeting the needs of consumption and food preparation with additional quantities needed to meet all hygiene needs [9]. Average daily consumption values such as those reported in the literature are important for developing sustainable water systems, however, diurnal usage patterns and peaking factors are critical in assuring that these water systems will adequately meet the needs of the clients.

From our field studies in Honduras, we showed that the villagers in this region use an average of 9.5 L of water per capita per day for consumption and food preparation needs with little left for hygiene. Comparatively, interviews of villagers in the Ugandan communities revealed that the average per capita use is approximately $26 \mathrm{~L}$ per day; these villages had improved water systems with centrally 
located taps in each community. The field studies in Honduras also showed that while most families treated their water by boiling or using chlorine bleach, a few families did not treat their water. For these Honduran villages, water is only collected during daylight hours (from 5:00 to 18:00) and the diurnal pattern of water collection revealed two distinct peaks with the highest number of water collection trips between six to eight in the morning and the second highest number of trips between two to four in the afternoon. Although the timing of water collection does not necessarily correlate to water usage, the frequency of water gathering in the early morning and mid-afternoon hours suggests water usage patterns similar to those in developed countries. If this pattern can be verified in other contexts, it may negate the need for field studies for usage patterns.

This data also allowed us to estimate the peak hour to average day usage ratio (peaking factor) that is critical for the design and analysis of water system components such as storage reservoirs and piping networks. For the three communities surveyed, the aggregate peaking factor was found to be 4.9. This is very different from the peaking factor of 2.25 currently used in the design of rural water systems in Honduras [10], which suggests either that new water systems may not be meeting the peak demands of clients, or that having water piped directly to the point of use results in water demand being more evenly distributed throughout the day since water use is not necessarily equivalent to water collection. Additional studies are needed regarding post-development diurnal water usage in order to obtain more realistic peaking factors for future design.

In summary, because of cultural and geographical differences in the use of water (as an example, irrigation is not significant in the Honduran villages), average per capita use and diurnal demand will most likely require that some field data are collected. Below is a summary of the recommended method to collect focused field data regarding diurnal water usage:

(1) Involve the local NGO or water agency in developing the water usage surveys. Cultural nuances may have a profound effect on how water users will interpret questions regarding the collection, treatment, and household use of water.

(2) Use someone who is local to the area to conduct the interviews in the native language to insure proper interpretation of the questions and answers.

(3) Have the local NGO or water agency gain the community's approval for the study and select a representative sample of water users if the entire community cannot be surveyed.

(4) Be prepared to measure the volume of water collection vessels, as users may not have standard sized containers. You cannot assume that the user knows the exact volume of water collected; however, they do know the number of containers used for each water-gathering event.

A copy of the survey used in Honduras can be obtained by contacting the third author of this article.

\subsection{User Travel}

Without access to clean water, many people are exposed to diarrheal microbes that can cause severe health risks [11]. One of the other major benefits associated with improved water supply is the reduction of time and effort required to gather water that enable water users to increase production, improve education levels, or enjoy more leisure time. Reducing the need for gathering water can also have health benefits beyond waterborne illnesses in terms of lower back pain associated with water gathering [12]. 
Although some data exists in the published literature regarding the time spent on water gathering, this data is specific to a particular geographical area (Kenya) and is not universally applicable [13]. With our own examples in Uganda and Honduras, we found that the collection time is quite different for improved water systems as compared to unimproved systems. Besides the differences between improved and unimproved systems, the terrain is vastly different between the two regions. Field studies of travel time are needed to establish water collection times for specific locations. However, we suggest that this travel time data can be extrapolated to larger geographic areas if travel time, or more specifically walking speed, can be correlated to topographic parameters such as average slope of terrain traversed by the water user.

To demonstrate this correlation, we completed time of travel studies in Honduras. We also analyzed walking speeds with respect to the age of the carrier, however age did not appear to be an important factor as no statistical difference could be determined between individuals under and over the age of 20 . The general terrain of the communities that we studied can be described as mildly steep and hilly with travel routes that are generally unimproved footpaths and have minimal queuing times at the water sources. The greatest distance travelled during our field study was $0.775 \mathrm{~km}$ with a total round trip travel time of 31 minutes. Our studies revealed that walking speed can be correlated to average terrain slope in situations where the route traveled has a consistent slope (up or down). Linear coefficients of correlation between walking speed to the water source and slope ranged from 0.704 to 0.758 . Somewhat lower coefficients of correlation were found for walking speeds from the water source ( 0.517 to 0.686$)$. We found that the decrease in walking speed ranges from $0.0125-0.032 \mathrm{~m} / \mathrm{s}$ percent change in slope for average slopes ranging from 0 to $20 \%$. The overall average walking speed ranges from $0.84 \mathrm{~m} / \mathrm{s}$ (from source) to $0.96 \mathrm{~m} / \mathrm{s}$ (to source). Because of frequent afternoon thunderstorms when we collected the field data (summer), nearly all of the footpaths were muddy and slippery. During the dry season, we expect that walking speeds are probably higher.

Field specific data such as that determined in the Honduran study is likely more applicable to Central American locations than generic data reported in the published literature, which tends to originate from Africa or Asia. However, as shown with the Honduran example, quantifying user travel in metrics of walking speed as a function of terrain rather than simply reporting the average round trip travel time for a particular region or population provides a tool for evaluating time savings based on local or regional characteristics. In other words, correlations between terrain and walking speed such as those derived from the Honduran studies are probably fairly robust for other regions in Central America with similar topography and climate because the cultural and genetic background of the rural population is relatively homogenous. Below is a summary of the recommended method to collect focused field data regarding water collection time:

(1) Have the local NGO or water agency gain the community's approval for the study and select a representative sample of water users if the entire community cannot be surveyed.

(2) Plan a reconnaissance trip before the water-gathering event. If the goal of the study is to correlate walking speed with terrain slope, than other factors such as stream crossings, barb wire fences, inconsistent slope (e.g., up-and-down topography) may eliminate some routes from the study. 
(3) Do not interfere with the water gatherer's normal routine, by engaging in conversation, providing assistance or attracting attention from other people, especially children. This aspect of the study can feel uncomfortable to the investigator, since it is a normal instinct to want to offer help or interact with the water gatherer.

(4) Timing of the water-gathering event must account for potential delays due to conversations with other villagers, periods of rest, and queuing at the water source.

(5) A reliable GPS unit should be used for elevation and distance measurements. Again, reconnaissance is critical to determine potential interference of GPS signals from forest canopy.

(6) Using longer routes (round trip time greater than $15 \mathrm{~min}$ ) increases the correlation between terrain slope and walking speed.

\subsection{Water System Preference}

Even though an improved water source is available and functioning, community members may opt to use unimproved sources instead. As discussed in the literature, these choices can be due to a variety of factors, such as inability or unwillingness to pay (discussed next) and/or mistrust of the system [14]. Therefore, field studies are needed if it is necessary to create a demand function for different water choices.

In the Ugandan field study, we used two methods to determine the extent to which the available improved water sources are used. First, we asked community members questions regarding their relationship with the water system to gauge their involvement with the system and the corresponding service delivery. All communities have access to untreated water within $30 \mathrm{~min}$ and interview results show that this water is still used widely for hygiene purposes despite having water from improved systems within seven minutes. Second, we compared water system income (that is, the amount of money collected at the tap stands) with seasonal rainfall records. The correlation between the two suggests that community members continue to rely on rainwater harvesting when rainwater is available. Nonetheless, in the interviews, most community members reported that they purchase at least some of their drinking water from the tap stands (improved systems).

Based on our experience, when collecting field data regarding household water usage and preferences with surveys as described in Section 4.1, one should also request access to the water system records maintained by the community water board to compare with the interview results. These records should also be compared with other evidence of potential external influences, such as rainfall.

\subsection{Willingness to Pay}

Community-based management is common for rural villages in low-income countries due to the failure of centrally organized governments to maintain remote, small-scale water supplies [15]. This form of management implies that communities should take responsibility for the operation and maintenance of the water supply. It is often implemented when the community forms a water board, in which a group will select a caretaker and collect and manage their own fees from water users. It has been argued in the literature that communities should have a sense of ownership of the water source for them to assume responsibility for operation and maintenance [16]. Therefore, in addition to willingness to pay at the tap stand when water is gathered, information about willingness to pay for system repairs can provide an indication of the level of commitment of community members to the improved water 
system. Once again, field studies are needed if it is necessary to create a willingness to pay function given the differences between communities. As an example, in our Uganda fieldwork, we interviewed community members about their willingness to pay for system repairs separately from their water purchases. Across the three communities, an average of $94 \%$ of those interviewed reported that they would be willing to pay an additional fee to help fund system repairs; the amount, however, varied widely among individual users.

Based on our experience, when collecting field data regarding household water usage and preferences with surveys as described in Section 4.1, one should also include a set of questions related to both willingness and ability to contribute financially for repairs to the water system.

\section{Field Studies for Water System Characteristics}

As stated, the locally specific data (inputs and outputs) about water system characteristics that are typically needed for sustainability assessments include:

- water source type

- water source quantity (seasonal, flow)

- water source quality (pathogens, other contaminants)

- improved vs. unimproved

- collection type

- treatment type (potable vs. non potable)

- distribution type

- distance to improved water system (if applicable)

- water system capacity (proxy: potential number of households can serve)

- number of households served

- water system condition

- demand vs. supply (daily vs. seasonal)

- system failure (service disruption)

- environmental impact (habitat loss, pollutant loading, water loss/transfer)

We noted earlier that cost data for improved water systems may be less critical in terms of field study needs since such data is typically available in the literature and from foundations. The work by Jones et al. confirms this assumption, as does the field study in Uganda [2,7]. However, the Uganda field study gave us a unique opportunity to observe the differences that water system choices can have on long-term costs because the charitable organization that financed the water projects in the villages we visited in Uganda, the Fontes Foundation, has continued to work with these communities to promote sustainability. While the initial capital costs for water systems in the developing world often are born by charitable organizations, it is less common for these organizations to continue to fund the systems after implementation. In other words, typically, once the system is up and running it is turned over to the community and the charitable organization moves on to its next project.

The community water boards (discussed later) in the Ugandan communities are required to submit monthly reports to the foundation's office in Kampala. These reports include income from water sold, costs of chemicals and energy, and maintenance costs. We transcribed data from village pumping records, receipts kept in the foundation office, and caretaker record books that track daily water sales. 
Following the IRC's WASHCost life cycle cost scheme, we categorized the financial data into capital expenditures, operating and minor maintenance expenditures, capital maintenance expenditures, and expenditure on direct support [9,17]. Not surprisingly, the majority of costs for the Ugandan communities are operating costs. However, we were able to inquire about the circumstances and how the money for unanticipated expenditures is obtained. For example, when a generator in one village failed, the Fontes Foundation paid for a replacement because the community was not able to cover the cost. In another community, extensive repairs to a faulty pump were financed internally. In the third community, the cost of replacing a pump was split between the community and the Fontes Foundation.

The Ugandan field study revealed that case-specific information is needed about which entity pays for both routine and unanticipated expenditures to understand whether a community's water system can be self-supporting, whether the community is likely to be able to sustain the system as components deteriorate over time, and whether there is an active support group in-country to provide the needed training and ongoing support. In other words, some locally collected cost data is an important complement to other more generic sources for that data. This data may be obtained in the community being studied, or from the offices of the sponsoring organization.

The Ugandan field study also illustrated the importance of all components of the water system including the power source. One of the many challenges to using pumps in rural areas is the lack of a reliable power supply. This affects not only user satisfaction with the system in terms of system functionality and reliability, but also the cost to operate the system and the variability of those costs over time. Of the three communities we visited in Uganda, one has its water system connected to the power grid, one has a solar-powered system, and the other relies exclusively on a generator for power to drive the pumps. Because grid power is unreliable, the community that is connected to the grid also maintains a backup generator for which it must purchase fuel; the generator is used frequently. One of the other two communities uses solar power to run its pumps when the weather is amenable and a backup generator at other times. This unreliability of power supply leads to high variability in operating costs because more fuel is required to power the generator in some months than in others. Fuel is not locally available and must be transported at variable costs. Further, a breakdown in the electricity production of the solar panels led to high costs in a particular month because the generator backup was used until the system was repaired. The third community must run a generator to power the system, which leads to high fuel costs and significant wear and tear on the generator, which leads to higher maintenance expenditures as well.

The field studies showed that energy costs, if indeed a necessary part of the water system will vary significantly from one community to another because of the differences in the costs of the energy choice. This information helps to predict future costs for the system and to assess its economic sustainability. While ranges of costs can be obtained from the literature, the choices of energy sources are community specific and vary from one community to another. Based on our experience, we recommend that when interviewing the community water board include the following:

(1) Interview community members to determine the technical abilities and education level of the water system technicians.

(2) Review financial records to determine energy costs and relative level of use for each method employed in the community. 


\section{Field Studies for Water Board Characteristics}

The locally specific data about the water board characteristics that are typically needed for sustainability assessments include:

- infrastructure repair capacity

- tariff level decision metrics

- removal of household from service decision metrics

- availability of repair/O\&M expertise

- availability of spare parts

In the Uganda field study, we interviewed water board members in each of the three communities to gain insight into their commitment towards operating the water schemes, and to assess whether the water boards would be able to cover capital maintenance costs in the future (as described above). In all three communities, water board members have been elected and they meet regularly with good attendance. In one of the communities, residents have opted to make the terms of the current members indefinite. In this community, standard response to any service interruption is to call a meeting immediately to determine the course of action. In another community, because there is a trained technician, most repairs can be completed internally; however, the board has not determined a way to fund larger capital maintenance costs.

For all three of these communities, the Fontes Foundation provides ongoing mandatory training and technical and financial assistance, as needed. The technical assistance is particularly valuable because many of the villagers have received at most a primary education. While this ongoing support keeps the systems functioning, the expectation is that eventually the communities will be able to sustain the systems themselves. A dedicated and capable water board is instrumental to ultimate independence from the supporting institution and long-term sustainability. Ideally, a community would be self-sufficient with respect to the operation and maintenance of its water system. However, the Uganda field study shows that this can require significant time and education. There is no way to assess the skills, knowledge, and dedication of a community's water board without field studies. As such, we recommend that when interviewing the community water board, include questions to determine the regularity of meetings and the level of attendance by committee members to meetings. Also, interview water board members to understand "first response" strategies when a problem arises with the water system and develop a corresponding metric to analyze their circumstantial effectiveness.

\section{Conclusions}

As stated, our goals for this project include identifying the critical data needs for sustainability assessment, evaluating what can be obtained from the literature versus what should be obtained from field studies, and discussing some best practices for such data collection. Based on the extensive field data set for Malawi along with previously published reports, we determined the key characteristics about a community water system (from a life cycle perspective) for which data is needed according to water users, the water system, and the water board.

The water use surveys, time of travel studies, and studies regarding water system selection and willingness to pay provide examples of focused studies that yielded necessary data for assessing the 
sustainability of rural water systems. The water system characteristics gathered from written records obtained on site provide an example of data that could potentially be obtained without visiting the community, but only if records are kept and transmitted to a central, accessible location. Further, these studies showed that detailed information about choices for each system component and O\&M decision is essential in predicting future system costs. In terms of water board characteristics, although the three villages studied in Uganda were very similar demographically, minor differences between the board's perceived commitments corresponded to critical differences in the water service delivery. As expected, there is no substitute for conducting field studies to collect these critical locally specific input and output data, however caution is needed when relying on user-reported information versus objective observations; ideally one needs a combination of data sources.

Regarding best practices, we suggest that the published literature should be used as a valuable source for aggregate information that helps the assessment team to understand the context for that country, region, and community, and as a starting point for the design of field studies so that focused interview protocols and other data collection instruments can be developed. We also found that field studies in these communities are only successful with local translators since interviews are a key component of such studies given the importance of behavior and how that behavior affects various water system choices. Another best practice is that our partners in the three field sites introduced us, the translators, and the overall field studies to the communities using their long-standing relationships to gain cooperation. Having such ground support is critical to the success of these types of field studies in terms of getting willing participation. However, such cooperation may also influence the responses in unknown ways both good and bad that must be recognized when analyzing the results, e.g., those interviewed might feel that they should say positive things because of the connection to the donor groups.

As shown, the challenge in evaluating the sustainability of such water systems lies in balancing the accuracy of the assessments using focused field studies versus the time and monetary costs in obtaining such data. As an example, the time of travel studies were extremely time-consuming and conducting such studies to assess every new water project in a region of interest is simply not feasible. However, with additional, strategically located, time of travel studies, we believe that a robust relationship between travel time and terrain can be developed that would be applicable across much of Central America. Likewise, establishing a field-focused database of metered post-development water use and demand patterns could provide a more realistic estimate of average per capita demand and peaking factors in contrast to the standard values reported in the published literature. These best practices need to be considered by the relevant development organizations that maintain such resources.

In summary, it appears that, despite the costs, field studies are essential for gathering a large portion of the data needed to assess water system sustainability in rural communities in the developing world. These field studies can be more effective if critical data needs are sought from the beginning of the study. The literature provides a starting point, but differences in culture, climate, and terrain on a large scale, and community social dynamics on a small scale, can lead to very different outcomes for systems that might appear at first to be similar. While this paper has focused on what data is needed for assessment, our hope is that the results of field studies such as ours will contribute to improved tools that can be used to further the goal of providing sustainable water systems for rural villages in low-income countries. 


\section{Acknowledgments}

The authors credit the support of the following research grants, NSF HSD 0729458 and NSF IRES 0926451. We acknowledge our colleagues, Jeffrey Pfaffmann and Christopher Ruebeck, for their modeling work that helped set up the need for this work. We also acknowledge the work of multiple undergraduate students who assisted in gathering field data throughout these studies. And, we acknowledge the help provided by Water for People and the Fontes Foundation.

\section{Conflicts of Interest}

The authors declare no conflict of interest.

\section{References and Notes}

1. Taylor, B. Addressing the Sustainability Crisis: Lessons from research on managing rural water projects. Available online: http://www.wateraid.org/ /media/Publications/sustainability-crisis-rural-watermanagement-tanzania.pdf (accessed on 12 September 2013).

2. Jones, S.; Abseen, A.; Stacey, N.; Weir, L. A life-cycle approach to improve the sustainability of rural water systems in resource-limited countries. Challenges 2012, 3, 233-260.

3. Masduqi, A.; Endah, N.; Soedjono, E.; Hadi, W. Structural equation modeling for assessing of the sustainability of rural water supply systems. Water Sci. Tech. Water Supply. 2012, 10, 815-823.

4. Schweitzer, R.; Mihelcic, J. Assessing sustainability of community management of rural water systems in the developing world. J. Water Sanit. Hyg. Dev. 2012, 2, 20-30.

5. 2008 Population and Housing Census: Preliminary Report. Available online: http://unstats.un.org/unsd/ demographic/sources/census/2010_phc/Malawi/Malawi_Report.pdf (accessed on 12 September 2013).

6. Weir, L. Predicting Rural Water System Sustainability: Evidence from Blantyre Malawi. Undergraduate Thesis, Lafayette College, Easton, PA, USA, 2011.

7. Lantz, K. Financing Strategies for Sustainable Rural Water Systems. Undergraduate Thesis, Lafayette College, Easton, PA, USA, 2013.

8. Nyong, A.; Kanarroglou, P. Domestic water use in semi-arid Africa: a case study of Katarko village in northeastern Nigeria. Hum. Ecol. 1999, 27, 537-555.

9. Howard, G.; Bartram, J. Domestic Water Quantity, Service Level and Health; World Health Organization: New York, NY, USA, 2003.

10. Reents, N.W. Design of Potable Water Systems in Rural Honduras. Master Thesis, Michigan Technological University, Houghton, MI, USA, 2003.

11. Haller, L.; Hutton, G.; Bartram, J. Estimating the costs and health benefits of water and sanitation improvements at global level. J. Water Health. 2007, 5, 467-480.

12. Hoy, D.; Beyer, H.; Morgan, C.; Tool, M. The back happy tap stand. J. Water Supply Res. T. 2005, 54, 261-263.

13. Whittington, D.; Mu, X.; Roche, R. Calculating the value of time spent collecting water: some estimates for Ukunda, Kenya. World Dev. 1990, 18, 269-280.

14. Fonseca, C.; Franceys, R.; Batchelor, C.; McIntyre, P.; Klutse, A.; Komives, K.; Moriarty, P.; Naafs, A.; Nyarko, K.; Pezon, C.; et al. Briefing Note 1a Life-cycle Costs Approach: Costing 
Sustainable Services, November 2011. Available online: http://www.washcost.info/page/1557 (accessed on 4 November 2013).

15. Harvey, P.; Reed, R. Community-managed water supplies in Africa: Sustainable or dispensable? Community Dev. J. 2007, 42, 365-378.

16. Marks, S.; Davis, J. Does user participation lead to sense of ownership for rural water systems? Evidence from Kenya. World Dev. 2012, 8, 1569-1576.

17. IRC. Life-Cycle Costs Approach; IRC International Water and Sanitation Centre: Hague, The Netherlands, 2011.

(C) 2013 by the authors; licensee MDPI, Basel, Switzerland. This article is an open access article distributed under the terms and conditions of the Creative Commons Attribution license (http://creativecommons.org/licenses/by/3.0/). 